\title{
The Functional Movement Screen and Injury Risk in Sporting Populations: An Evidence-to-Practice Review
}

\author{
Taylor Niles, MS, SCAT, ATC; Federico Rossi, SCAT, ATC; Zachary K. Winkelmann, PhD, SCAT, ATC
}

University of South Carolina, Columbia, SC

\begin{abstract}
The Functional Movement Screen (FMS) is a functional test, which aims to identify dysfunctional, asymmetrical, and painful movements that could contribute to future injuries. Medical professionals can clinically use this information to implement appropriate, specialized prehabilitation training aimed at reducing the dysfunctional, asymmetrical, and painful movements, to help prevent injury risk. Research on this tool, however, has contradictory findings regarding FMS composite score and future risk of injury. It is unclear to what extent FMS can predict those with future injury risk, and whether there are factors, such as age, sex, or sport-type, which may be contributing to these varying findings. Therefore, the purpose of this review was to identify which factors, if any, may contribute to the contradictory findings regarding the relationship between FMS composite score and subsequent injury risk in physically active populations. The review aimed to include any study which performed an FMS test at baseline on physically active individuals competing at any level, and determined risk groups based on composite scores, using odds ratios, sensitivity, and specificity as outcome measures. Subgroups were assessed based on athlete age, sex, sport-type, injury definition and injury mechanism. Reviewed participants were split into two age groups, senior (18+ years old) and junior (9-18 years old) athletes. It was found that age, sex, and sport-type explained some of the variable findings in the literature, however, effect sizes were often small in magnitude. Functional Movement Screen composite scores and asymmetry seemed to be the most useful in estimating injury risk for senior athletes, as well as individuals participating in rugby, American football, and ice hockey. There were many gaps identified in the research that may help get a consensus on optimal populations and uses for FMS. Thus, we recommend utilizing appropriate clinical judgment when determining if FMS would be a beneficial tool for identifying those with higher injury risk at your clinical site and with your patient population.
\end{abstract}

\section{Key Phrases}

Preparticipation exams and screening, functional testing, injury risk reduction

\section{Correspondence}

Dr. Zachary Winkelmann, 1300 Wheat Street, Columbia, SC 29208.

E-mail:winkelz@mailbox.sc.edu

Twitter: @zachwinkelmann
Full Citation

Niles T, Rossi F, Winkelmann ZK. The functional movement screen and injury risk in sporting populations: An evidence-to-practice review. Clin Pract Athl Train. 2021;4(2): 52-57. https://doi.org/10.31622/2021/0004.2.8.

Submitted April 20, 2020 Accepted: March 8, 2021.

\section{ORIGINAL REFERENCE}

Moore E, Chalmers S, Milanese S, Fuller JT. Factors Influencing the Relationship Between the Functional Movement Screen and Injury Risk in Sporting Populations: A Systematic Review and Meta-analysis. Sports Med. 2019;49(9):1 449-1463

\section{SUMMARY}

\section{CLINICAL PROBLEM AND QUESTION}

\section{Musculoskeletal screening tests such as the}

Functional Movement Screen (FMS), are designed to identify modifiable risk factors so that healthcare providers can implement appropriate training strategies to reduce the incidence of injury. ${ }^{1,2}$ The FMS is composed of 7 subtests, including the squat, step over, in-line lunge, reach, leg raise, push-up, and rotary stability, where each test is scored on a scale 1-3, to produce a maximum score of 21. Functional Movement Screen pain and asymmetry are dichotomous outcomes based on the presence or absence of pain during FMS testing and at least one FMS test difference between left and right sides of the body, respectively. While FMS is one of the more popular injury risk screening tools, there is little agreement on what factors of the test contribute to injury risk; therefore, the primary purpose of this meta-analysis was to identify factors that contribute to the investigated relationship
Clinical Practice in Athletic Training Volume 4 - Issue 2 - September 2021 
between FMS and injury risk in sporting populations, especially the difference between the senior (18+ years old) and junior (9-18 years old) athletes. The second aim of this study was to examine the results of studies that have assessed the relationship between FMS asymmetry and injury risk.

\section{SUMMARY OF LITERATURE}

The authors for the guiding systematic review and meta-analysis conducted a systematic search of Medline, Scopus, EBSCOhost (including SportDiscus, Academic Search Premiere, Health Source: Consumer Edition, Health Source: Nursing/Academic Edition), Embase and Web of Science databases, to identify whether participant age, sex, sport-type, injury definition and mechanism contributed to the variable findings. Studies that were included in the systematic review had to meet the following inclusion criteria: 1) peer reviewed and published in the English language, 2) participants were competing at any level of sporting competition, 3) prospective cohort study design that assessed FMS performance at baseline using the complete FMS test battery and subsequently observed participants during sports training and competition, 4) identified risk groups based on FMS composite score, asymmetry or pain, and 5) outcome measures were injury incidence that could be categorized within the six injury level classifications provided by Orchard and Hoskins. ${ }^{3}$

Systematic database searches identified 1028 potential studies that, after screening, resulted in 36 studies included in the systematic review. Nine of 36 studies did not explicitly state that participants were injury-free at the time of testing. Five of 36 studies were deemed to not describe the injury surveillance method in enough detail. Four of 36 studies used a follow-up period that was less than one complete competitive season. Twenty-three studies were unclear whether follow-up was completed for all participants, and 18 were unclear whether strategies to account for

Copyright $(\subset)$ by Indiana State University All rights reserved. ISSN Online 2577-8188 incomplete follow-up were implemented. Six studies did not utilize statistical analysis that resulted in the reporting of injury-risk statistics.

\section{SUMMARY OF OUTCOMES}

This review looked at the odds ratio for injury risk given a specific criteria of FMS testing, to see if any differences in effect size existed between participant age, sex, sport type, injury definition or injury mechanism. The review also looked at the sensitivity and specificity based on risk groups determined by the different FMS testing criteria. The FMS criteria analyzed included a 1) FMS composite score threshold of $\leq 14,2) \geq 1$ subtest with reported asymmetry, or 3 ) $\geq 1$ subtest with reported pain. Injury mechanism was grouped as either all-cause injury or non-contact injury. Injury definitions were divided into tissue damage or presentation to medical staff, limited or loss of training/match, and limited or loss of match only.

\section{FINDINGS AND CLINICAL IMPLICATIONS}

This review looked to identify factors that contribute to the contradictory findings regarding FMS composite score and subsequent injury risk in sporting populations. Kiesel et al found that individuals with a composite score of $\leq 14$ have an 11 times greater injury risk, while a systematic review by Bonazza, et al. reported a 3-fold or smaller increase in injury risk. 4,5 There could be a few reasons for the differences in the findings between these studies. For example, the systematic review mentions how only 2 other studies replicated the findings of Kiesel, et al. via independent ROC curves. The review also identifies how there may be an effect of sex and population characteristics on a cutoff. This could have contributed to the differences between the studies, as Kiesel, et al. focused only on male professional football players who form one individual team, while Bonazza, et al. included studies with men and women, as well as athletes 
and non-athletes. Overall, this review identified that there were few studies that show a significant relationship between composite scores and subsequent future injury risk, and many of the results that were significant were only of small effect size. While the general understanding is that FMS testing's purpose is to identify dysfunctional, asymmetrical, and painful movements that could contribute to future injuries, more focused research is needed investigating which aspects of FMS testing work best at identifying risk and for which subgroups of individuals.

There are several gaps in the literature that still need to be identified to justify FMS use in many settings. First, of the studies used in this review, 3 studies used only female participants, 1-3 while 18 used only males, ${ }^{4-21}$ which leaves a sex bias in the literature, making it difficult to generalize females. It should also be considered that individual subtests of the FMS may have stronger association with injury risk due to the differing demands and injury risks presented in varying sports. More consideration should be focused on whether poor scores for specific subtests are more strongly associated with injury to the region of the body that was tested. While there are a few studies which investigate this, $6-9$ there is still a general lack of literature looking into subtests and their relation to specific injury types and body regions. Finally, the results of this study showed a smaller effect for junior athletes (OR $=1.03$ [0.67-1.59]; $p=0.881)$ compared to senior athletes $(O R=1.80$ [1.17-2.78]; $p=0.008)$, however, there is little research that explains why we see this difference.

Based on the findings of this meta-analysis, our own review of the evidence, and clinical expertise, we suggest that clinicians consider their patient population and possible contributing risk factors which may lead to injury in their setting before implementing FMS. The contradictory findings of research on this topic, as well as the lack of clinically significant findings of this meta-analysis,

Copyright $\left({ }^{\circ}\right.$ by Indiana State University All rights reserved. ISSN Online 2577-8188 identify various gaps in the research on FMS testing. A composite score threshold of $\leq 14$ was only found to have significant increase in injury risk for males, senior athletes, male and female rugby players, and baseball players. Composite scores were also found to be a better predictor of allcause injuries, than non-contact injuries. There is not enough evidence to support a relationship between subtest and corresponding injury to subtest body region, though we recommend looking at the individual subtest scores, rather than just the composite score to best understand where an individual's movement deficiencies lie. Because of these findings, we suggest clinicians consider FMS testing for senior male athletes, especially those who participate in rugby or baseball. Although the findings were not significant for other sport-types and subgroups, we recommend that sports or groups which have higher incidence of all-cause injuries should consider FMS testing as well. Functional Movement Screen testing is a feasible test, so the general loss and harm of implementing FMS, even for subgroups that did not have a significant relationship to injury risk prediction, is minimal.

\section{CLINICAL BOTTOM LINE}

Functional testing has the potential to be a helpful tool in identifying at-risk individuals for future injury, thus allowing healthcare providers to create tailored prevention programs to address movement disparities identified by the screening tool. It should be considered, however, that fullbody movement screens, such as the FMS, may not be the best tool for all population groups. Due to inconsistent and unclear methodology of the various research into FMS testing, it is difficult to create a clear consensus on the effectiveness of the tool as a predictor for future injury in many subgroups of individuals. Overall, most effect sizes were only small in magnitude and unlikely to be clinically meaningful in most sports, except for rugby, American football, and ice hockey. This could be due to the similarities between these 
sports mentioned and the 7 components of the FMS test.

It may be beneficial for clinicians to consider assessing for movement quality based on the subtests instead of the composite score. Different subtests assess for different movement qualities, such as range of motion, strength, or balance. Identifying movement qualities that are crucial to specific sports and using only the FMS subtests which assess those movement qualities may be more beneficial for sport types that did not have significant results with the composite score. Similarly, if a sport consists of upper extremity use, it may be more beneficial for clinicians to focus the examination on the movement quality of the upper extremity using subtests that specifically assess the upper extremity. We are not suggesting that injury prevention be hyperfocused to a singular joint, rather there is a need to examine the kinetic chain and how movement patterns at the ankle can affect the hip, and so on. We suggest that clinicians consider the individual subtest of the FMS as a better tool than the composite score of the FMS. For example, the hurdle step of the FMS is a multi-joint assessment that could be very helpful for a lower extremity activity like ballet or soccer, which the guiding review did not identify as having a clinically meaningful finding. Reviewing subtests individually would allow the clinician to identify movement patterns which most affect the patient, rather than performing a complete FMS test to get a composite score.

The composite score and presence of asymmetry are strong predictors of injury risk in senior compared to junior athletes, though again, this effect size was small in magnitude. Junior cohorts may benefit from a lower composite score threshold, as suggested by the consistent null findings in junior athletes. There have been many false positives in junior cohort studies, in relation to FMS composite scores and injury risk, so creating a new composite threshold for junior athletes may produce more significant findings

Copyright $($ b by Indiana State University All rights reserved. ISSN Online 2577-8188 and make the screening tool more useful in these cohorts. It is likely that the painful scores seen in junior athletes is related to poor neuromuscular control as they develop, rather than dysfunctional movements. Many of the FMS subtests use body weight and asymmetrical movements are a result of motor control deficits which may lead to increased injury risk. Since senior athletes are exposed to higher game speeds and increased force impacts, a stronger relationship between FMS composite scores and injury risk in this population may be expected. Injury mechanism and definition do not have a significant impact on the relationship between FMS testing and injury risk, and due to the sex bias in the literature, findings from this review indicate a stronger correlation with male athletes than female athletes.

\section{REFERENCES}

1. Cook G, Burton L, Hoogenboom B, Voight $M$. Pre-participation screening: the use of fundamental movements as an assessment of function-part 1. N Am J Sports Phys Ther. $2006 ; 1(2): 62-72$

2. Cook G, Burton L, Hoogenboom B, Voight $M$. Functional movement screening: the use of fundamental movements as an assessment of function-part 2. Int J Sports Phys Ther. $2014 ; 9(4): 549-63$

3. Moore E, Chalmers S, Milanese S, Fuller JT. Factors influencing the relationship between the functional movement screen and injury risk in sporting populations: A systematic review and meta-analysis. Sports Med. 2019;49(9): 1449-1463. https://doi.org/10.1007/s40279-019$01126-5$.

4. Kiesel K, Plisky P, Voight M. Can serious injury in professional football be predicted by a preseason Functional Movement Screen? N Am J Sports Phys Ther. 2007;2(3): 1 47-58

5. Bonazza NA, Smuin D, Onks CA, Silvis ML, Dhawan A. Reliability, validity, and injury

Clinical Practice in Athletic Training Volume 4 - Issue 2 - September 2021 
predictive value of the Functional Movement Screen: a systematic review and metaanalysis. Am J Sports Med. 2016;45(3):72532.

https://doi.org/10.1177/0363546516641 937.

6. Tee JC, Klingbiel JF, Collins R, Lambert MI, Coopoo Y. Preseason Functional Movement Screen component tests predict severe contact injuries in professional rugby union players. J Strength Cond Res. 2016;30(1 1):3194-203. https://doi.org/10.1519/JSC.0000000000 001422.

7. Hotta T, Nishiguchi S, Fukutani N, Tashiro $Y$, Adachi D, Morino S, et al. Functional Movement Screen for predicting running injuries in 18-to 24-year-old competitive male runners. J Strength Cond Res. 2015;29(10):2808-15. https://doi.org/10.1519/JSC.0000000000 000962.

8. Rusling $C$, Edwards KL, Bhattacharya A, Reed $A$, Irwin $S$, Boles $A$, et al. The functional movement screening tool does not predict injury in football. Prog Orthop Sci. 2015;1(2):41-6. https://doi/org/10.5455/pos.2015080311 3054.

9. Schroeder J, Wellmann K, Stein D, Braumann KM. The Functional Movement Screen for injury prediction in male amateur football. Dtsch Z Sportmed. 2016;67(2):39-43. https://doi.org/10.5960/dzsm.2015.200.

10. Chorba RS, Chorba DJ, Bouillon LE, Overmyer CA, Landis JA. Use of a functional movement screening tool to determine injury risk in female collegiate athletes. $\mathrm{N} \mathrm{Am} \mathrm{J}$ Sports Phys Ther. 2010;5(2):47.

11. Clay H, Mansell J, Tierney R. Association between rowing injuries and the Functional Movement Screen ${ }^{\mathrm{TM}}$ in female collegiate division I rowers. Int I Sports Phys Ther. 2016;1 1(3):345.

12. Walbright $P D$, Walbright $N$, Ojha $H$, Davenport T. Validity of functional screening

Copyright (C) by Indiana State University All rights reserved. ISSN Online 2577-8188 tests to predict lost-time lower quarter injury in a cohort of female collegiate athletes. Int J Spots Phys Ther. 2017;1 2(6):948.

13. Kiesel KB, Butler RJ, Plisky PJ. Prediction of injury by limited and asymmetrical fundamental movement patterns in American football players. $J$ Sport Rehabil. 2014;23(2):88-94. https://doi.org/10.1123/isr.2012-0130.

14. Chalmers S, Fuller JT, Debenedictis TA, et al. Asymmetry during preseason Functional Movement Screen testing is associated with injury during a junior Australian football season. J Sci Med Sport. 2017;20(7):653657.

https://doi.org/10.1016/i.jsams.2016.12.0 $\underline{76}$.

15. Chalmers S, Debenedictis TA, Zacharia A, et al. Asymmetry during Functional Movement Screening and injury risk in junior football players: A replication study. Scand J Med Sci Sports. 2018;28(3):1281-1287. https://doi.org/10.1111/sms.13021.

16. Lee C-L, Hsu M-C, Chang W-D, et al. Functional movement screen comparison between the preparative period and competitive period in high school baseball players. J Exerc Sci Fit. 2018; 16(2):68-72. https://dx.doi.org/10.1016\%2Fi.jesf.2018. $\underline{06.004}$.

17. Azzam MG, Throckmorton TW, Smith RA, Graham D, Scholler J, Azar FM. The Functional Movement Screen as a predictor of injury in professional basketball players. Curr Orthop Pract. 2015;26(6):619-623. http://dx.doi.org/10.1097/BC0.00000000 $\underline{00000296 .}$.

18. Martin C, Olivier B, Benjamin N. The functional movement screen in the prediction of injury in adolescent cricket pace bowlers: an observational study. J Sports Rehabil. 2017;26(5):386-395. https://doi.org/10.1123/isr.2016-0073.

19. Slodownik R, Ogonowska-Slodownik A, Morgulec-Adamowicz N. Functional Movement Screen ${ }^{\mathrm{TM}}$ and history of injury in Volume 4 - Issue 2 - September 2021 
the assessment of potential risk of injury among team handball players. $J$ Sports Med Phys Fitness. 2017;58(9):1 281-1286. https://doi.org/10.23736/s00224707.17.07717-9.

20. Avery $M$, Wattie N, Holmes $M$, Dogra S. Seasonal changes in functional fitness and neurocognitive assessments in youth icehockey players. J Strength Cond Res. 2018;32(11):3143-3152. https://doi.org/10.1519/isc.00000000000 02399.

21. Dossa K, Cashman G, Howitt S, West B, Murray N. Can injury in major junior hockey players be predicted by a pre-season functional movement screen-a prospective cohort study. J Can Chiropr Assoc. 2014;58(4):421.

22. Duke SR, Martin SE, Gaul CA. Preseason functional movement screen predicts risk of time-loss injury in experienced male rugby union athletes. J Strength Cond Res. 2017;31(10):2740-2747. https://doi.org/10.1519/isc.00000000000 01838.

23. Hotta T, Nishiguchi S, Fukutani N, et al. Functional movement screen for predicting running injuries in 18-to 24-year-old competitive male runners. J Strength Cond Res. 2015;29(10):2808-2815. https://doi.org/10.1519/isc.00000000000 $\underline{00962 .}$.

24. Tee JC, Klingbiel JF, Collins R, Lambert MI, Coopoo Y. Preseason Functional Movement Screen component tests predict severe contact injuries in professional rugby union players. J Strength Cond Res. 2016;30(11):3194-3203. https://doi.org/10.1519/isc.00000000000 01422.

25. Kolodziej $M$, Jaitner T. Single Functional Movement Screen items as main predictors of injury risk in amateur male soccer players. Ger J Exerc Sport Res. 2018;48(3):349-357. https://doi.org/10.1007/s12662-0180515-2.
26. Philp F, Blana D, Chadwick EK, et al. Study of the measurement and predictive validity of the functional movement screen. BMJ Open Sport Exerc Med. 2018;4(1):e000357. https://dx.doi.org/10.1 136\%2Fbmisem2018-000357.

27. Rusling C, Edwards K, Bhattacharya A, et al. The functional movement screening tool does not predict injury in football. Prog Orthop Sci. $2015 ; 1(2): 41-46$. http://dx.doi.org/10.5455/pos.201508031 13054.

28. Smith PD, Hanlon MP. Assessing the effectiveness of the functional movement screen in predicting noncontact injury rates in soccer players. J Strength Cond Res. 2017;31(12):3327-3332. https://doi.org/10.1519/isc.00000000000 01757. 